\title{
Inter-organizational information systems in meat chains: the linkage between supply chain organization and system requirements
}

\author{
Jan Bahlmann and Achim Spiller \\ Department of Agricultural Economics and Rural Development, University of Goettingen, Germany; j.bahlmann@agr.uni-goettingen.de
}

\begin{abstract}
The German meat sector is faced with increasing cost pressures and a high demand for quality and safety. Both issues require powerful and holistic IT solutions in order to achieve knowledge transfer, process alignment and transparent information flows across the supply chain. In recent years, new Inter-Organizational Information Systems (IOS) were developed for the red meat industry. However, the acceptance of IOS at the farm level is still relatively low. Since there is hardly any relevant literature on IOS in the meat sector, this study contributes to the general research on IOS, the status quo of data flows in the pork supply chain as well as a systematization and evaluation of the most relevant existing internet based IOS. Furthermore, special needs for IOS on the spot market which is the dominating organizational form in the German pork sector are defined and contrasted against the current supply of systems. It was found that none of the existing IT solutions adequately meet the requirements which are important in complex spot market relationships. Consequently, we recommend a higher consideration of supply chain organization in IOS research and development.
\end{abstract}

Keywords: data exchange, internet, spot market, track \& trace, quality assurance

\section{Introduction}

The globalization of the meat trade, intensive cost competition at the food retail level and non-transparent production processes require a more efficient utilization of, and a reliable access to, product and process information in meat supply chains. Germany has suffered around 25 separate meat scandals since 2005 (Dittberner 2008) resulting in a considerable loss of reputation for the meat sector (Albersmeier and Spiller, 2008). This has led to an urgent need for action to control the flow of goods, its associated data and the quality of suppliers across the meat chain. Furthermore, the European Commission has passed the EU Hygiene Regulations EC 852-854/2004, which generally require methods for company (internal) as well as chain wide quality assurance systems.

In recent years, various Inter-Organizational Information Systems (IOS) have been introduced into the market. Yet, there is little understanding of their scope which ranges from unidirectional transfer of slaughter and meat inspection results to seamless tracking and tracing. Empirical studies involving German pig farmers revealed that the adoption rate of these systems is about 28\% (Bahlmann et al., 2009). It is argued that one of the major reasons for the relatively low acceptance and diffusion of IOS is related to the organizational structures of the meat sector which complicate the development and implementation of appropriate systems (Bahlmann and Spiller, 2008;
Bahlmann et al., 2009). In respons to this, the motivation of the following paper addresses the linkage between supply chain organization and the development of IOS.

Holistic information systems which are capable of managing data and information across the supply chain as a whole could more easily be realized in vertically integrated supply chains. For this part of the market, the implementation is almost exclusively a matter of technical realization, since there are clearly defined supply chain structures, stable business relationships and focal companies which have the power to implement and coordinate new Information and Communication Technologies (ICT). According to Bowersox and Closs (1996), focal companies are supply chain actors which initiate inter-firm relationships, have a sufficient size or economic power to coordinate and harmonize the IT environment.

However, focal companies such as Danish Crown which controls the vast majority of the Danish pork production, do not exist in Germany. The spot market on which $90 \%$ of the German pork is traded is the most relevant channel in terms of the total effects on food quality and safety. Its coordination is very complex, characterized by intense division of labour, unstable relationships and a very dynamic supply chain structure.

Therefore, we analyzed whether there are appropriate systems which, albeit only partly, meet the requirements for IOS in spot markets or whose technical approaches 
may be transferred for the development of a spot market compatible system.

\section{Objectives and methodological framework}

Firstly, an insight will be provided into the general and sector specific literature on IOS and the requirements for spot market compatible information systems in meat supply chains. The literature review is followed by an analysis of the status quo of inter-stage data transmission in the German pork supply chain, based on 11 expert interviews with CEO's and department managers of the meat (7) and IT (4) sector. In the main part of this study, the most important IOS for pork supply chains are analyzed and classified into three main clusters. The underlying information was collected by means of personal interviews with the providers, system documentations, company websites and software testing if the opportunity was provided.

Finally, the scope of the analyzed systems is contrasted with the requirements to be met by IOS in spot markets. Based on this, recommendations are made for further research.

\section{Inter-Organizational Information Systems}

\section{Definition and delineation}

In recent years, Information Systems have been the subject of intensive discussion in information economics and computer science. This increase in interest can be traced back to the growing relevance of information as an important competitive factor (Blake and Learmonth, 1984) in increasingly complex and globalized markets.

The term 'Information System' was coined in the mid 1960s by Langefors' 'Theoretical Analysis on Information Systems' in which he defines an Information System as a medium to collect, store, process and distribute information sets (Langefors, 1966: 143). The IOS are a subcategory of Information Systems and underline the management of information from a multi-organizational perspective. In this study, IOS are treated as 'automated information systems shared by two or more companies' (Cash and Konsynski, 1985: 134) that 'extend beyond traditional enterprise boundaries' (Hong, 2002) and provide operative and strategic information about relevant resources.

The various opportunities for information and data transfer in IOS require a further differentiation into classic and computer based communication channels which will become relevant for the demonstration of the status quo of data and information flows in the following chapter. Traditional communication channels include for example the use of face-to-face and telephone conversation, mail and fax. In contrast, computer based communication methods comprise the digital transfer of data through a company's internal intranets or the WWW using stationary (e.g. desktop computer) or mobile devices (e.g. mobile phone, PDA). Furthermore, the literature on Information Systems distinguishes between non-internet based IOS, such as classic EDI on the one hand and Internet Based InterOrganizational Information Systems (IBIS) on the other hand (Soliman and Janz, 2004: 698).

\section{Requirements to be met by Inter-Organizational Information Systems}

Inter-Organizational Information Systems for the meat sector should account for various methods to improve the quality and safety of production and increase the total chain value. Therefore, one of the most important requirements is the integration of a chain wide, seamless tracking and tracing system (Salampasis and Ocak, 2007). The framework should include the electronic exchange and automated processing of quality related process data across the stages to improve supply chain transparency as well as the efficiency of integrated quality assurance and certification.

Furthermore, interoperability with external databases (Salampasis and Ocak, 2007) and existing ICT within the supply chain has to be established in order to facilitate the access to information beyond company borders, enhance knowledge transfer (Warkentin et al., 2001), collective learning (Simatupang et al., 2002: 293) and the use of 'Netchain' effects (Lazzarini et al., 2001). For the same reason, actors should have the ability to interact by means of both sending and receiving data (cf. Barrett and Konsynski, 1982; Warkentin et al., 2001).

The spot market is characterized by specific demands on IOS. In contrast to vertically integrated systems, in which one system is generally implemented and coordinated by a supply chain leader, actors on the spot market are free to use proprietary developments, standard IT solutions, or even abandon the use of IOS. If there are no sector specific IT standards, as is the case in many agribusiness sectors, electronic data exchange across the entire supply chain is hardly realizable. Therefore, IT companies generally take the key role as Application Service Providers (ASP) to coordinate data across the stages and keep the IOS compatible with environmental changes.

Sometimes, the development of powerful systems is initiated by the retail, slaughterhouses or livestock marketing agencies. However, the services for interorganizational data exchange are exclusively provided to their marketing partners. Thus, the availability of readyto-use, easily adaptable IOS is a critical factor on the spot market. And even if non-exclusive concepts exist, smaller stakeholders, such as farmers, livestock marketing agencies 
or veterinarians have a limited willingness to make specific investments into the customization process. On the spot market, these facilities should have the opportunity to join a network solution (standardized) and independently set up the system according to their needs.

Since the open market is more dynamic than a vertically aligned system, there is a special requirement for flexibility and extensibility of the system structure (cf. Salampasis and Ocak, 2007). A quick response to environmental impacts, such as changing trading partners or legal conditions, has to be guaranteed.

Also more importantly in contrast to hierarchical organizations is the acceptance of IOS, since participation is non-mandatory. Therefore, IT solutions for the open market should provide a clear economic benefit such as the reduction of transaction costs. The implementation process and usability should be guaranteed with minimal effort and be able to be to a large extent self-administrated.

Finally, it must be considered that the system has to deal with sensitive information which independent actors do not want to disclose to all participants of a network. Attention should therefore be paid to special demands on data security and self-administration of data access rights.

Consequently, a spot market compatible system should meet the following conditions:

- Seamless tracking and tracing of products, product related data and information across the entire supply chain.

- Interoperability with external systems on the market.

- Interaction (data and information transfer to and from relevant actors).

- Non-exclusiveness (availability to every actor).

- Limited specific investments for customization (affordability for small enterprises).

- Flexibility and extensibility.

- Profitability and total cost efficiency.

- Data security management (self-administration of data access rights).

\section{Research on Internet Based Information Systems in agribusiness}

General attention towards e-business in agricultural economics and information science has increased in recent years. There is a broad range of literature focused on the adoption of information and communication technologies. Among these studies, some are directed towards the acceptance and diffusion of IT in the agricultural input industry (Akridge, 2003); whilst others refer to the acceptance at farm level (Fick and Doluschitz, 2007) or by small and medium sized agribusiness enterprises (Doluschitz et al., 2005; Vlachos et al., 2007). However, the research which targets the inter-organizational dimension of Information Systems, especially IBIS, in the agrifood chain is very limited (Storer, 2006).

For instance, Theuvsen et al. (2007) analyzed the exchange of mandatory, certification related data across the stages. It was found that electronic information transfer in the German meat sector is 'still in its infancy and is mainly restricted to providing online access to or email transmission of slaughter documents' (ibid.: 568).

In the application oriented research, Poignée et al. (2003) have discussed the development of an inter-organizational, web based quality communication system for a regional grain flour processor who established a vertically aligned partnership with his suppliers (ibid.: 582). The conceptual framework consists of the subsystems 'track \& trace', 'quality assurance', 'quality coordination' and 'quality improvement' which are tied to a centralized database. In a parallel study the authors provide a simplified semantic model for the implementation of the web based system (Hannus et al., 2003). However, the study describes an application prototype which was developed under controlled conditions for a specific vertically aligned chain. It is therefore limited in terms of generalization and transfer to a spot market situation.

Very few studies broach the topic of web based supply chain management in the red meat sector. Schulze Althoff and Petersen (2004) developed a food chain information system for animal health management and risk based meat inspection in the pork industry. The study proposes a centralized data management system which integrates the first stages of the supply chain of pig production (breeding) to slaughter but does not include the secondary processor, wholesale, food retail and consumer levels.

In 2007 there was a scientific report on the project SiTRA, which is viewed as a first attempt to provide an internet based spot market compatible information system. The web application was designed to establish traceability for regional brands in 8 large Italian food chains (Giannerini, 2007). SiTRA achieves compatibility with the existing IT Systems at the stakeholder level by means of special web services which are capable of producing supply chain specific XML data schemes. A Graphic User Interface (GUI) provides the means to design and extend traceability data flows for, and facilitates the establishment of connections between, various supply chains.

All in all, there is still no study which contributes to a conceptual framework for the implementation of IOS in spot markets. Before entering the analysis of the existing IT systems in the main part of this paper, the following section provides a general overview of the supply chain framework, communication channels as well as the sources, possible destinations and the flow of important meat chain data. 


\section{Supply chain characteristics, communication channels and data flows}

In general, the German red meat sector is characterized by a high degree of division of labour, predominant spot market organization and non-transparent marketing channels. The number of actors in the supply chain ranges from 214 slaughterhouses (with a minimum of 20 employees) to 52,700 pig fatteners (Destatis, 2007). Some organizations require a more detailed explanation, since they are specific to the German market (cf. Figure 1).

- Livestock marketing agencies such as private livestock dealers or farmer associations build an intermediate stage between farmers and slaughterhouses on which approximately $90 \%$ (Traupe, 2002) of the slaughter pigs in north western Germany are purchased (pooled), partly traded among each other, and resold to slaughterhouses.

- The Qualität und Sicherheit GmbH (QS) provides the most important certification system in the German meat sector which covers almost the entire supply chain. Amongst other things, QS coordinates salmonella monitoring across laboratories, farmers and slaughterhouses.

- Official veterinarians are responsible for mandatory carcass meat inspection before slaughter (German meat hygiene regulation 'Fleischhygienegesetz' from 30.06.2003).

- HI-Tier is a nationwide and mandatory internet database to control livestock movements from breeding to slaughter. A certain pool of data and information is also to some extent specific to the German meat sector and likewise requires explanation.

- The term 'special certificates' describes information on certificates beyond that of QS. In Germany there are approximately 30 different certification systems (Theuvsen et al., 2007) which require the transfer of additional process data across the supply chain - at least the basic information on the certification status.

- The 'standard supply note' is the farmers' confirmation of or comment on mentionable limitations to the hygienic safety of a certain batch of slaughter pigs which have been prepared for delivery. The note must be transferred at least 24 hours before delivery to the corresponding slaughterhouse which then has to forward it to the official veterinarian (EC 853/2004).

- The 'carcass grading results' are a collection of meat quality data which are measured at the beginning of the slaughter process. The data furthermore serve as critical target values for the fattening process and build the basis for the final pay off beyond the live and dead weight, respectively.
Figure 1 contains a summary of the empirical and literature based findings about data flows and communication channels on the spot market of pork production. The left side of the illustration shows the supply chain structure, whilst the right side includes all those stages which are affiliated but not directly involved in the production process. The sources and possible destinations of relevant data were described for each of the supply chain actors. The right columns in each block labelled 'provide' include information which is provided from the respective level to the corresponding trading partners, then in turn, placed in one of the left columns described as retrieve (cf. Figure 1). The letters in brackets ( $I=$ feed industry; $F=$ farmers; $\mathrm{L}=$ livestock marketing agencies; $\mathrm{S}=$ slaughterhouses; $\mathrm{P}=$ meat processors; $\mathrm{R}=$ food retail) mark the source and destination of data which is provided by more than one facility. The map does not include the classic, transaction related information such as order or invoice data which are generally processed at every stage of the supply chain.

On the one hand, the analysis reveals media breaks across the entire supply chain. Figure1 shows that the farmers' data is exchanged with the feed industry and livestock marketing agencies but is not transferred to secondary processors, the food retail or the consumer. Due to the relatively high importance of intermediate livestock marketing agencies in Germany, even data and information transfers from farmers to slaughterhouses are rare. This non-transparent situation is mainly due to the limited legal requirements on data transmission and a general reluctance towards voluntary data exchange (cf. Bahlmann et al., 2007, 2009). The European law, for instance, only requires the actors to prove to the next direct supplier of resources 'one step up' and the recipient of finished goods 'one step down' the supply chain (EC 178/2002).

As a result, there are limited possibilities to track and trace products and product related data across the entire supply chain. Manual requests lead to considerable time delays and relatively high expenses. Furthermore, advanced livestock health related information (e.g. mortality, drug application, finishing time, carcass meat inspection history, salmonella monitoring history) which would be essential for e.g. the recently introduced approach to risk based meat inspection (EC 854/2004 further specification in EC 1244/2007) or general certification related processes, is mainly transferred by means of traditional methods. Hence, many processes are almost impossible to automate and require considerable effort.

On the other hand, the analysis shows that the total range of meat chain data which has to be collected, entered, and transferred down the supply chain declines from the farmer to the food retail level. This coincides with the number of contacts which is up to two times higher at the primary 


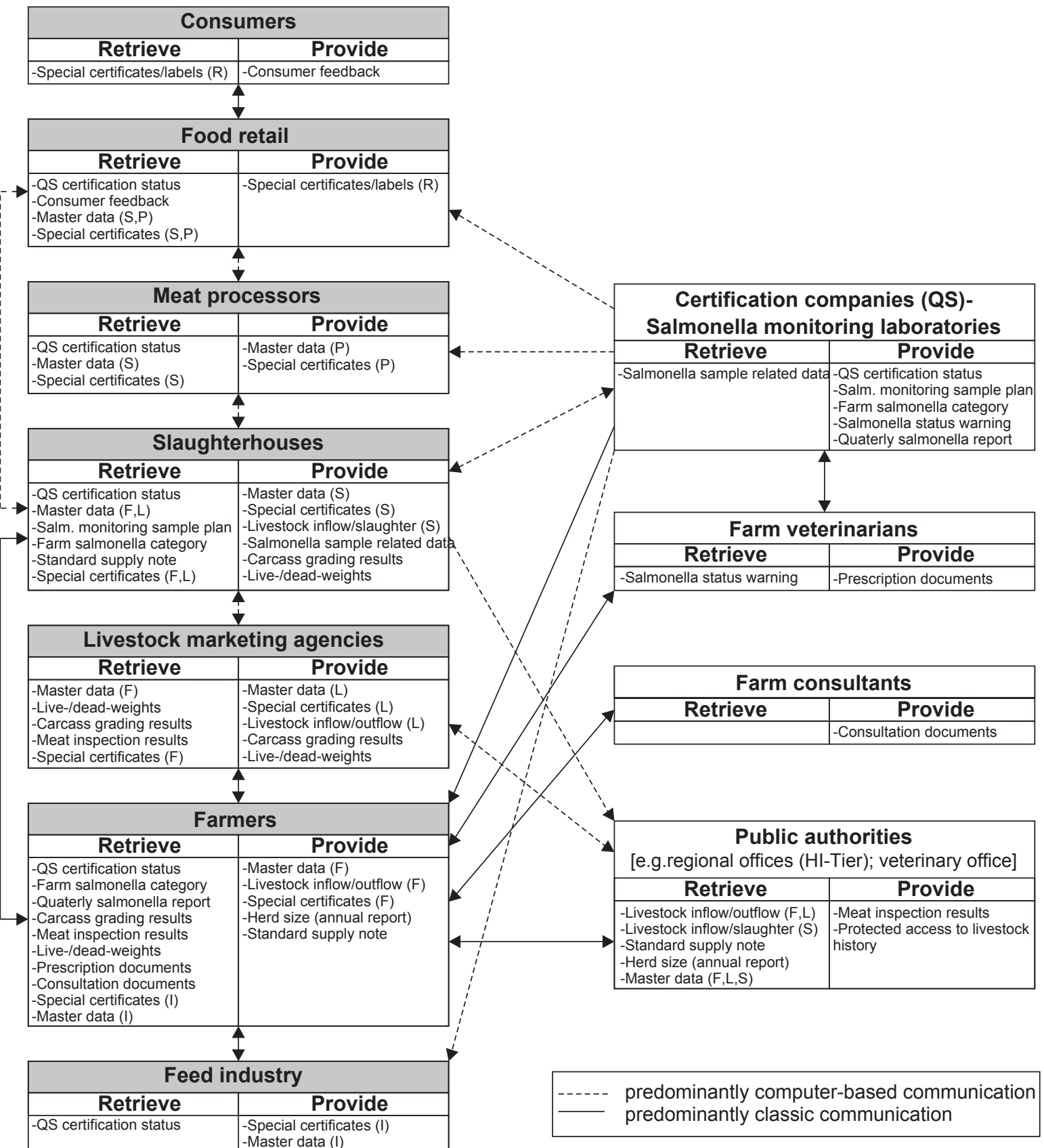

Figure 1. Status quo of information transfer and communication channels (results based on expert-interviews, expert-

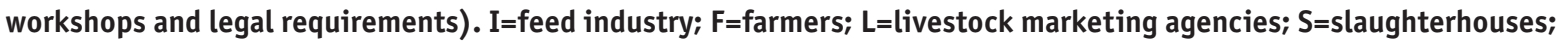
$P=$ meat processors; $R=$ food retail.

producer level in comparison to food retail. Farmers generally communicate with several other institutions beyond their suppliers and customers. For example, animal inflow/outflow and fattening process data (standard supply note) have to be transferred to the public authorities (HITier database and official veterinarians). Additionally, farmers regularly receive prescription documents from farm veterinarians as well as audit reports and salmonella monitoring results from certification companies (e.g. QS). Thus, the majority of and also the most critical meat chain data have to be entered at the first stages of the supply chain. For this reason, the acceptance of IOS at 
the primary producer level determines the final success in terms of seamless, IT supported traceability. However, new information and communication technologies are still not sufficiently accepted at the farm level (cf. agriMA, 2005; Stricker et al., 2003; Fick and Doluschitz, 2007). In reference to the empirical results of a recently conducted survey among 873 pig producers in Germany, the adoption rate of Internet Based Inter-Organizational Information Systems (IBIS) is about 28\% (authors' own analysis in 2008). Farmers still prefer the use of traditional communication channels for the exchange of information and data with slaughterhouses, marketing agencies, QS and other business partners (cf. dashed and continuous lines in Figure 1).

One of the major reasons for this phenomenon may be the inadequacy of the supply of IOS for the requirements of the spot market. The following chapter first provides a general overview on the existing IBIS which is later contrasted with the requirements of spot markets.

\section{Existing Internet Based Information Systems in the German meat sector}

In the past decade, some slaughterhouses, public agencies and IT companies have developed different types of IBIS to improve the efficiency of data communication across the meat supply chain. To the best of our knowledge, there is no study which systematically analyzed these systems. Therefore, a general description was carried out by means of the criteria of system type, development, system owner, availability, main addressees, channel characteristics, and main functions (cf. Table 1).

In the following, the IT solutions are classified into three main categories characterized in detail and contrasted with the requirements of IOS which were discussed in the beginning.

\section{Cluster 1: Web-databases (systems 1-2)}

The first cluster comprises two nationwide known and quasi-mandatory web databases with a clearly defined scope of functions. Qualiproof is a central internet database for salmonella monitoring in the pork sector. Its main function is to coordinate salmonella monitoring results and sample plans between slaughterhouses, laboratories, and farmers. The database is accessible by means of both a common website login and a SOAP/XML interface which provides access to external systems. HI-Tier is another web database provided by public authorities to electronically record the inflow and outflow of livestock from the pig and cattle breeder stage to slaughterhouses. Additionally, livestock husbandry capacities on the farming level have to be transmitted annually. Those facilities which are obliged to report animal movements can access the database by means of a web frontend or locally installed batch processing software.

Both systems have a relatively narrow focus and are not designed to provide any other than the above named features. They exclusively aim at increasing the efficiency of quality assurance and control of epidemics. Therefore, tracking and tracing is only possible in terms of animal movements and salmonella monitoring from the agricultural input industries to slaughter (cf. Table 2). However, the databases are important isolated IT systems which provide open interfaces and can therefore be easily integrated into holistic IOS for the spot market. Due to their clearly defined focus, system modifications and extensions play a negligible role. In any case, if changes are needed they have to be adapted by every actor in the market.

\section{Cluster 2: Unidirectional data transfer between farm and slaughterhouse (systems 3-5)}

In the second cluster there are three IT solutions whose common denominator is the transfer of carcass grading and meat inspection results from slaughterhouse to farm. Pig farmers can use these tools to control their slaughter results, compare themselves with other farm colleagues or check their livestock health by means of salmonella monitoring and meat inspection analysis. Beyond some minor variation in the functional range, the main difference was identified in terms of availability. While 'Extranet' and 'Farmingnet' are exclusively provided to suppliers of two major slaughterhouses (Westfleisch and Vion), SchlachtdatenOnline is an independent framework.

None of these systems was developed for tracking and tracing of resources. Data is transferred from slaughterhouses to farmers, but no interaction takes place. Since farmers do not in general use complex IT systems, interoperability is relatively easily established by means of web frontends. Flexibility and extensibility are mainly critical for holistic systems which include data transfer across the entire supply chain. Since no more than 2 stages are involved in cluster 2 , the original meaning of this requirement is not fulfilled. Indeed, farmers stand to benefit from electronic data reception and analysis of slaughter and meat inspection results, but detailed profitability calculations and the integration of salmonella monitoring reports (except for Westfleisch Extranet) are not supported. However, due to the lack of interaction, slaughterhouses only indirectly benefit from their investments, as the quality of supplies may increase. As a result of exclusiveness (Westfleisch Extranet and Farmingnet), lack of interaction between the stages and very limited supply chain coverage, the approaches in this 


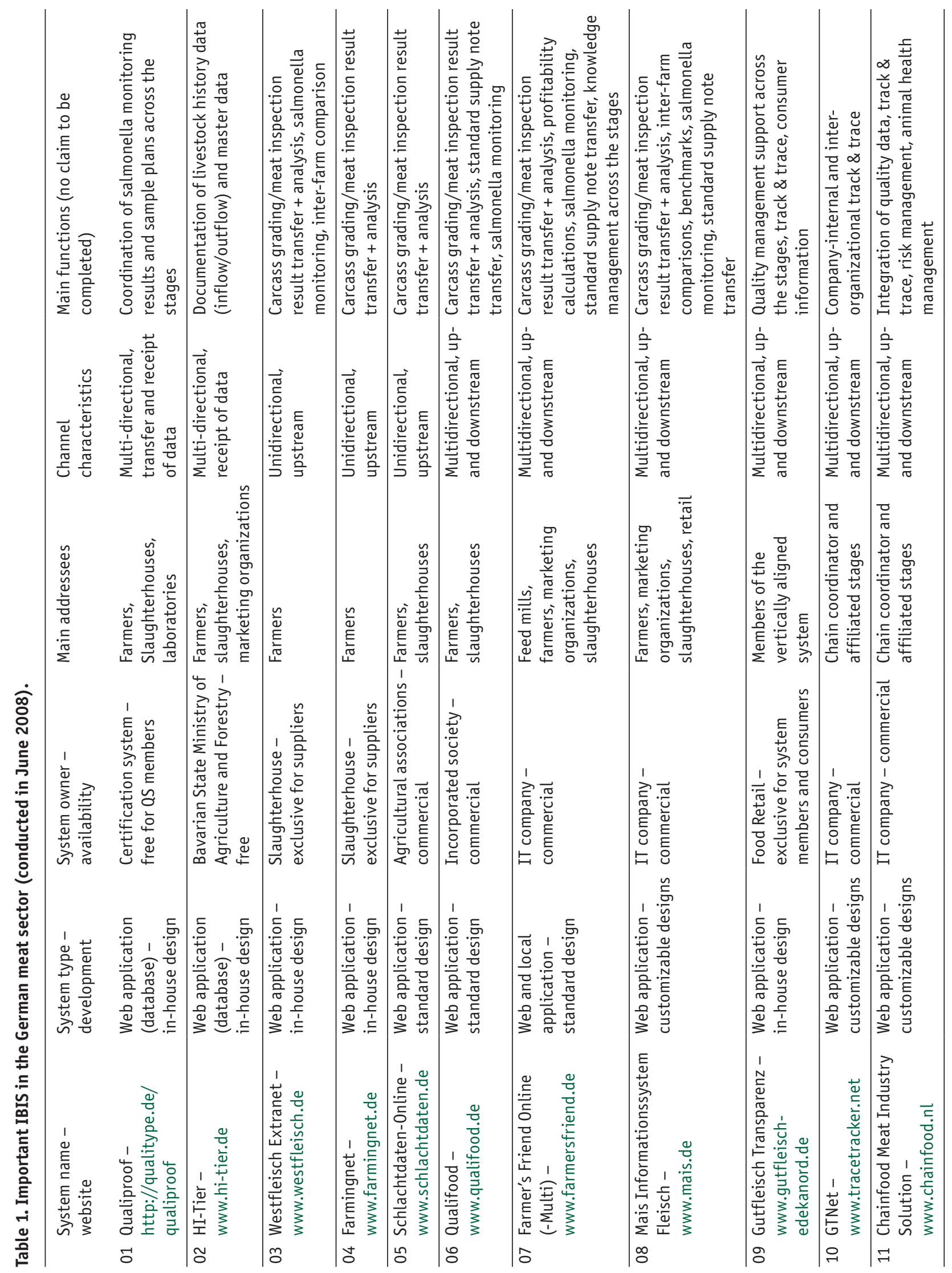


Table 2. Requirement compliance and spot market applicability of cluster 1 .

\begin{tabular}{|c|c|c|c|c|c|c|c|c|c|}
\hline Cluster & System & $\begin{array}{l}\text { Complete } \\
\text { tr. \& tr. }\end{array}$ & Interoperab. & Interaction & Non-excl. & $\begin{array}{l}\text { Lim. sp. } \\
\text { invest. }\end{array}$ & $\begin{array}{l}\text { Flexib. \& } \\
\text { extens. }\end{array}$ & $\begin{array}{l}\text { Profit. \& } \\
\text { cost eff. }\end{array}$ & $\begin{array}{l}\text { Dat. sec. } \\
\text { man. }\end{array}$ \\
\hline \multirow[t]{2}{*}{1} & Qualiproof & 0 & $\checkmark$ & $\checkmark$ & $\checkmark$ & $\checkmark$ & 0 & - & - \\
\hline & HI-Tier & 0 & $\checkmark$ & - & $\checkmark$ & $\checkmark$ & 0 & - & - \\
\hline
\end{tabular}

$\checkmark=$ fulfilled; $\bigcirc=$ partly fulfilled; -=not fulfilled.

Table 3. Requirement compliance and spot market applicability of cluster 2.

\begin{tabular}{llllllll}
\hline Cluster System & $\begin{array}{l}\text { Complete } \\
\text { tr. \& tr. }\end{array}$ & & Interoperab. Interaction Non-excl. & $\begin{array}{l}\text { Lim. sp. } \\
\text { invest. }\end{array}$ & $\begin{array}{l}\text { Flexib. \& } \\
\text { extens. }\end{array}$ & $\begin{array}{l}\text { Profit. \& } \\
\text { cost eff. }\end{array}$ Dat. sec. \\
man.
\end{tabular}

$\checkmark=$ fulfilled; $\bigcirc=$ partly fulfilled; -=not fulfilled.

cluster barely meet the requirements on holistic spot market compatible IOS.

\section{Cluster 3: Multidirectional data transfer across the stages (systems 6-11)}

The third and final cluster consists of six IT solutions which stand out from the above mentioned systems, since their general focus is on more than 2 stages. Furthermore, these systems enhance the interactive transfer of meat chain data up and down the supply chain (cf. Table 4). The scope of services and the structure within this group is quite different. Farmer's Friend Online/Multi, Mais Informationssystem Fleisch and Qualifood are generally related to the first cluster, since they consist of a very similar scope of functions. However, Mais Informationssystem Fleisch and Farmer's Friend Online/Multi are more comprehensive in terms of profitability calculations, result representation, processing of data to management information and additional marketing support for farmers. Furthermore, the Farmer's Friend components provide a knowledge management tool for piglet producers, pig fatteners, feed mills, veterinarians and marketing agencies which particularly aim at knowledge transfer and collective troubleshooting. In this framework, the participants have the opportunity to decide which users or user groups are allowed to access their data. Against the dual system structure of Farmers Friend, which includes the locally installed 'Multi' version for pig breeders, consultants, feed mills, slaughterhouses and livestock marketing agencies and the 'Online' version for farmers and consultants, Mais Informationssystem Fleisch is modularly structured. Dependent on customer requirements, the system is capable of integrating the complete supply chain, however a chain coordinator would be needed to initiate the extension to a holistic system.

Unique in the German red meat market is the holistic IBIS Gutfleisch Transparenz which has been specifically developed for the food retailer Edeka-Nord. Gutfleisch is a retailer owned brand by Edeka-Nord in which Gutfleisch Transparenz is primarily used to control the flow of goods and its related information across the vertically aligned supply chain. The system furthermore includes a consumer web portal on which it is possible to trace meat and meat products by means of the product code or the buying date back to a narrow pool of farms. At this aggregation level, certain information on the meat history such as animal genetics, feed and feed supplier, animal husbandry and animal health is available. However, the system is less flexible, as it was developed for a specific supply chain and is furthermore reserved for business partners of EdekaNord. The scope of functions is exemplary for a possible spot market system but the technical realization and implementation process strongly differs from the demands on open markets which are much more complex.

The 'Chainfood Meat Industry Solution' (abbr. Chainfood) and GTnet are closely related to each other, since both systems focus on tracking and tracing and are based on a generic technology approach. Similar to the Mais 
Table 4. Requirement compliance and spot market applicability of cluster 3.

\begin{tabular}{|c|c|c|c|c|c|c|c|c|c|}
\hline Cluster & System & $\begin{array}{l}\text { Complete } \\
\text { tr. \& tr. }\end{array}$ & Interoperab. & Interaction & Non-excl. & $\begin{array}{l}\text { Lim. sp. } \\
\text { invest. }\end{array}$ & $\begin{array}{l}\text { Flexib. \& } \\
\text { extens. }\end{array}$ & $\begin{array}{l}\text { Profit. \& } \\
\text { cost eff. }\end{array}$ & $\begin{array}{l}\text { Dat. sec. } \\
\text { man. }\end{array}$ \\
\hline \multirow[t]{6}{*}{3} & Qualifood & - & 0 & $\checkmark$ & $\mathrm{O}$ & $\checkmark$ & 0 & $\mathrm{O}$ & - \\
\hline & Farmer's Friend & - & 0 & $\checkmark$ & $\checkmark$ & $\checkmark$ & 0 & $\checkmark$ & $\checkmark$ \\
\hline & $\begin{array}{l}\text { Mais Informationssystem } \\
\text { Fleisch }\end{array}$ & - & O & $\checkmark$ & $\checkmark$ & O & O & $\mathrm{D}$ & D \\
\hline & Gutfleisch Transparenz & $\checkmark$ & O & $\checkmark$ & - & - & O & $\checkmark$ & - \\
\hline & GTNet & $\checkmark$ & $\checkmark$ & $\checkmark$ & $\checkmark$ & - & 0 & D & D \\
\hline & Chainfood & $\checkmark$ & $\checkmark$ & $\checkmark$ & $\checkmark$ & - & 0 & D & D \\
\hline
\end{tabular}

$\checkmark$ =fulfilled; $O=$ partly fulfilled; -=not fulfilled; $D=$ depends on customization.

Informationssystem Fleisch, Chainfood and GTnet are customizable to various supply chain requirements and furthermore are capable of linking all stages of a supply chain. The main application areas of Chainfood beyond tracking and tracing are risk management (e.g. epizootics), health/quality data integration and monitoring (e.g. risk based carcass grading) as well as cooperative animal health management. Chainfood uses centralized data management and a data by value technology, respectively. GTnet is specialized in intra- and inter-company tracking and tracing of products as well as product related data and is based on decentralized data by reference technology. Due to the generic structure, traceability models and data sets are customizable and therefore meet various requirements on traceability.

\section{Conclusions and recommendations for further research}

In this paper, 11 important Inter-Organizational Information Systems (IOS) were categorized into three main clusters and contrasted with the requirements of the spot market.

On the one hand, the analysis revealed that there is still no holistic IT supported IOS which is capable of establishing the seamless flow of meat chain information on the complex and hardly coordinated spot market. Instead, the German pork sector is compounded with various systems which are reserved for vertically integrated chains (e.g. Gutfleisch Transparenz, Westfleisch Extranet, Farmingnet). Chainfood, GTNet and Mais Informationssystem Fleisch provide customizable applications which generally require the initiation and coordination of a powerful supply chain leader (cf. Grant et al., 2006). Due to the special spot market requirements, such as interoperability, non-exclusiveness, flexibility, data security and limited specific investments for customization, the transfer of these approaches to a spot market solution is very limited.

On the other hand, there are some widely diffused systems, such as Qualiproof and HI-Tier which provide open interfaces for mandatory reporting processes. These web databases should be considered for the integration into holistic IOS for the spot market. Furthermore, the design of Farmer's Friend is to a large extent consistent with the needs of a spot market compatible IOS. The IT solution provides clearly defined services for data exchange and inter-stage collaboration between various actors of the agribusiness, is non-exclusive and considers special demands on data security management. Still, the application is not designed for traceability and does not go further than from the feed industry to slaughterhouses.

In general, the results of this study characterize the important linkage between the organizational structure of a supply chain and the requirements of IOS. It was revealed that the 'organizational fit' of supplied ICT is an important predictor for the adoption of new technologies which has to be considered in the development and implementation process. A catalogue of system requirements has been defined in the first part of this paper which may either be used to evaluate the appropriateness of IT systems for their application in non-contractual relationships or support the development of new spot market compatible IOS.

Further research has to be conducted on open IT standards to enable inter-stage data transmission across the meat chain as well as on the description and modelling of meat chain structures. However, the technical feasibility is only one side of the coin. From our point of view the question why holistic IOS so far failed to materialize beyond vertically integrated supply chains also has to be analyzed from the demand side. At this point, it remains unresolved if the inadequate supply is a classic example of market failure or 
if there is, contrary to our assumption, no sufficient demand for holistic IOS.

The presented research is based on the German market framework and therefore limited in terms of generalizability. The analysis considers spot market specific requirements on IOS which are also important in countries such as the Netherlands, Belgium or France but are less relevant in Denmark or the USA where almost the entire pork production is vertically integrated.

\section{References}

Agrima, 2005. Agrar mediafacts - Kommunikation mit der Landwirtschaft. Münster.

Albersmeier, F. and A. Spiller, 2008. Supply Chain Reputation der Fleischwirtschaft. Fleischwirtschaft, 07: 21-22.

Akridge, J.T., 2003. E-business in the Agricultural Inputs Industries. Review of Agricultural Economics, 25(1): 3-13.

Bahlmann, J. and A. Spiller 2008. The Relationship between Supply Chain Coordination and Quality Assurance Systems: A Case Study Approach on the German Meat Sector. In: M. Fritz, U. Rickert and G. Schiefer (eds): Innovation and System Dynamics in Food Networks 2008. Proceedings of the $2^{\text {nd }}$ International European Forum on System Dynamics and Innovation in Food Networks in Innsbruck-Igls (Austria), Bonn, pp. 189-200.

Bahlmann, J., A. Spiller and C.-H. Plumeyer 2009. Internet-basierte Informationssysteme in der Veredelungswirtschaft: Diffusion und Adoptionsfaktoren. In: Kuratorium für Technik und Bauwesen in der Landwirtschaft e.V. (eds) Landwirtschaft im Umbruch - Herausforderungen und Lösungen, Reinheim, pp. 247-270.

Bahlmann, J., B. Schulze and A. Spiller 2007. Trust as a supply chain management tool for slaughterhouses: Empirical evidence from north-western Germany. Paper prepared for the 17th Annual World Forum and Symposium 'Agribusiness Food Culture: Tradition, Innovation and Trust - A Positive Force for Modern Agribusiness', IAMA Conference in Parma (Italy), http://ifama.org/tamu/iama/conferences/2007Conference/ SymposiumPapers_files/1137_Paper.pdf, (verified June 15, 2009).

Barrett, S. and B. Konsynski, 1982. Inter-organisational informationsharing systems. MIS Quarterly, 6: 74-98.

Blake I. and G.P. Learmonth, 1984. The information system as a competitive weapon. Communications of the ACM, 27(12): 1193-1201.

Bowersox, D.J. and D.C. Closs, 1996. Logistical Management: The Integrated Supply Chain Process. McGraw-Hill Series in Marketing, New York. USA.

Cash, J.I. and B.R. Konsynski, 1985. IS Redraws Competitive Boundaries. Harvard Business Review, 63(2): 134-142.

Destatis, 2007. Database of the German state office of statistics [Online]. Available at: http://www.destatis.de (verified: October 29, 2007).
Dittberner, K.H., 2008. Nahrungsprobleme in den Medien. Available at: http://www.khd-research.net/Food/in_M/edia_01. html (verified: May 03, 2008).

Doluschitz, R., M. Emmel, F. Kaiser, J. Pape and M. Roth, 2005. The Emerging Role of E-Agribusiness - State of the Art and Perspectives in Germany. EFITA WCCA, July 25-28, 2005, Portugal.

Fick, J. and R. Doluschitz, 2007. Linking-up Animal Health Related Information to an Integrated Aimal-health System. In: S. Cox (ed.), Precision livestock farming '07, Wageningen Academic Publishers, Wageningen, the Netherlands, pp. 253-259.

Fleischhygienegesetz. Version of June 30, 2003. Bundesgesetzblatt Volume 2003 Part I No 32.

Grant, D.B., D.M. Lambert, J.R. Stock and L.M. Ellram, 2006. Fundamentals of Logistics Management (European Edition), Maidenhead, United Kingdom.

Hannus, T., O. Poignée and G. Schiefer, 2003. The Implementation of a Web Based Supply Chain Information System-Experiences with a Regional Quality Grain Program. In: Z. Harnos, M. Herdon and T.B. Wiwczaroski (eds.), EFITA 2003 Information technology for a better agri-food sector, environment and rural living, Debrecen-Budapest, Hungary, July 5-9, 2003, pp. 594-600.

Hong, I.B., 2002. A new framework for interorganizational systems based on the linkage of participants' roles. Information \& Management, 39: 261-271.

Langefors, B., 1966. Theoretical Analysis of Information Systems. Lund, Sweden.

Lazzarini, S.G., F.R. Chaddad and M.L. Cook, 2001. Integrating Supply Chain and Network Analysis: The Study of Netchains. Journal on Chain and Network Science, 1(1): 7-22.

Poignée, O., T. Hannus and G. Schiefer, 2003. Vertical Integrated Quality Management in Agribusiness: A Case Study. In: Z. Harnos, M. Herdon and T.B. Wiwczaroski (eds.) EFITA 2003: Information technology for a better agri-food sector, environment and rural living 2, Debrecen-Budapest, Hungary, July 5-9, 2003, pp. 581-587.

Regulation (EC) No 852/2004 of the European Parliament and of the council of 29 April 2004 on the hygiene of foodstuffs. Official Journal of the European Union, L139.

Regulation (EC) No 853/2004 of the European Parliament and of the council of 29 April 2004 laying down specific hygiene rules for food of animal origin. Official Journal of the European Union, L139.

Regulation (EC) No 854/2004 of the European Parliament and of the council of 29 April 2004 laying down specific rules for the organisation of official controls on products of animal origin intended for human consumption. Official Journal of the European Union, L139.

Regulation (EC) No 1244/2007 of 24 October 2007 amending Regulation (EC) No 2074/2005 as regards implementing measures for certain products of animal origin intended for human consumption and laying down specific rules on official controls for the inspection of meat. Official Journal of the European Union, L 281. 
Salampasis, M. and S. Ocak, 2007. An ontology based application framework for ICT-enabled traceability in the food supply chain. In: Proceedings of the $6^{\text {th }}$ Biennial Conference of the European Federation for Information Technology in Agriculture, Food and Environment, Glasgow, Scotland, July 1-5, 2007.

Schulze Althoff, G. and B. Petersen, 2004. Chain quality information system: development of a reference information model to improve transparency and quality management in pork netchains along the Dutch-German border. In: H.J. Bremmers, S.W.F. Omta, J.H. Trienekens and E.F.M. Wubben (eds.) Dynamics in Chains and Networks. Wageningen Academic Publishers, Wageningen, the Netherlands. pp. 166-174

Simatupang, T.M., A.C. Wright and R. Sridharan, 2002. The knowledge of coordination for supply chain integration. In: Business Process Management Journal, 8(3): 289-308.

Soliman, K.S. and B.D. Janz, 2004. Interorganizational Information Systems: Exploring An Internet-Based Approach. Issues in Supply Chain Management, 1(1): 1-5.

Storer, C., 2006. Information Communication Tools used to Coordinate Food Chains, Australasian Agribusiness Review, 14: Paper 2.

Stricker, S., M. Emmel and J. Pape, 2003. Situation of Agricultural Information and Communication Technology (ICT) in Germany. In: Z. Harnos, M. Herdon and T.B. Wiwczaroski (eds.) EFITA 2003: Information technology for a better agri-food sector, environment and rural living 2, Debrecen-Budapest, Hungary, July 5-9, 2003, pp. 690-698.

Theuvsen, L., C.-H. Plumeyer and J.-C. Gawron, 2007. Certification Schemes In The Meat Industry: Overview And Consequences For Chain-Wide Communication. Polish Journal of Food and Nutrition Science, 57(4): 563-669.

Traupe, C., 2002. Schlachtschweinevermarktung in Niedersachsen - Stand, Defizite, Entwicklungsmöglichkeiten. Cuvillier.

Vlachos, I., V. Zeimpekis, P. Chondros, M. Psarrou and N. Stragas, 2007. E-business adoption by small and medium food firms: Evidence from Greece, 6th Biennial Conference of the European Federation for Information Technology in Agriculture, Food and Environment, Glasgow, Scotland, July 1-5, 2007.

Warkentin, M., R. Bapna and R. V. Sugumaran, 2001. E-knowledge networks for inter-organisational collaborative e-business. Logistics Information Management, 14(1/2): 149-162. 
